\author{
Military Technical College \\ Kobry El-Kobbah, \\ Cairo, Egypt.
}

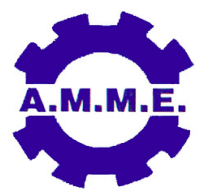

\title{
PREPARATION AND CHARACTERIZATION OF YTTRIA-CERIA DOPED TETRAGONAL ZIRCONIA / ALUMINA COMPOSITES
}

\author{
S. M. Naga*1, H. F. El-Maghraby*, M. Awaad*, M. A. Saleh**, \\ E. M. Abdelbary** and M. A. Tameem ${ }^{\star *}$
}

\begin{abstract}
Yttria-ceria doped tetragonal zirconia / alumina, $\left(\mathrm{Y}, \mathrm{Ce}-\mathrm{TZP} / \mathrm{Al}_{2} \mathrm{O}_{3}\right)$ composites were prepared via sol-gel and powder mixing techniques. The bodies were uniaxially pressed at $220 \mathrm{MPa}$. The formed green bodies were fired at $1500^{\circ} \mathrm{C}$ up to $1650^{\circ} \mathrm{C}$ with temperature interval of $50^{\circ} \mathrm{C}$ and firing rate of $5^{\circ} \mathrm{C} / \mathrm{min}$. The samples were evaluated for their densification, microstructure and phase constitution as well as their mechanical properties. ANSYS (finite element package) is utilized to simulate the temperature distribution along the material and so thermal conductivity of the material is calculated. The present study results showed an improvement in the properties of the samples prepared via sol-gel route compared with traditional powder mixing one. X-ray diffraction patterns of both sol-gel and mechanically mixed fired samples indicate the presence of cerium - zirconium oxide $\left(\mathrm{Ce}_{2} \mathrm{Zr}_{3} \mathrm{O}_{10}\right)$ phase and the absence of cerium aluminate $\left(\mathrm{CeAlO}_{3}\right)$ phase. It was concluded that the starting materials preparation route has a noticeable impact on the sintering behavior and mechanical properties of the final product.
\end{abstract}

\section{KEY WORDS}

Composites, Sol-gel technique, Microstructure, Mechanical properties, Thermal conductivity.

* National Research Center, Ceramics Dept., Cairo, Egypt.

** Egyptian Armed Forces.

1 Corresponding author: Salma M. Naga, National Research Center, Ceramic Dept., 12622-Cairo, Egypt. Email: salmanaga@yahoo.com, Tel.: 0020233322445 . 


\section{INTRODUCTION}

The rapid developments in ceramics have resulted in the emergence of newer materials suitable for engineering applications. Alumina $\left(\mathrm{Al}_{2} \mathrm{O}_{3}\right)$ is one of the widely used advanced ceramic materials because of its unique properties. The drawback of alumina is its brittleness. The low fracture toughness of the ceramic materials is due to the extremely limited dislocated motion in the material, which arises from the nature of the chemical bonds; which are ionic and / or covalent. Such problem can be overcome by designing and preparing the composite materials reinforced with fibers, whiskers and particulates of the same phase as that of matrix or of different suitable phase [1-3]. The dispersion of $10-20$ vol. \% of metastable tetragonal (t) zirconia particles in the alumina matrix improves both the fracture toughness and the strength of the alumina ceramics [4]. The effect of zirconia is based on the tetragonal to monoclinic phase transformation, accompanied by an increase in the specific volume of the order of 3-6\%. The produced volume increase generates a compressive stress in the ceramic matrix near the interface between $\mathrm{ZrO}_{2}$ and $\mathrm{Al}_{2} \mathrm{O}_{3}$ and makes the propagation of crack is difficult [5].

Rare earth elements, working as a series of effective additives, have got widespread applications in research of advanced ceramic materials. They can be used not only as stabilizers of the tetragonal zirconia, but also as sintering aid for $\mathrm{Al}_{2} \mathrm{O}_{3}, \mathrm{TiC}, \mathrm{TiB}$, $\mathrm{SiC}, \mathrm{Si}_{3} \mathrm{~N}_{4}$ and AIN ceramics [6,7]. Cerium oxide is one of the most reactive rare earth metal oxides. Due to its hardness and stable structure, ceria could be utilized in zirconia and/or alumina- zirconia systems [8]. Akin et al added ceria to the alumina matrix as a secondary phase with yttria stabilized zirconia. The results showed that the addition of ceria led to significant inhibition of alumina grain growth and the formation of elongated $\mathrm{CeAl}_{11} \mathrm{O}_{18}$ grains. Formation of elongated $\mathrm{CeAl}_{11} \mathrm{O}_{18}$ grains resulted in lower Vickers hardness and fracture toughness values than that of the non-containing composites [9].

To compensate the disadvantages of lower strength and lower hardness in Ce-TZP, caused by the addition of the second phase, the form controls of $\mathrm{Al}_{2} \mathrm{O}_{3}$ particles have been investigated. It was shown that the toughness can be improved by incorporation of the elongated and/or plate-like $\mathrm{Al}_{2} \mathrm{O}_{3}$ phases which were produced in situ sintering by the addition of a small amount of metal oxides [10,11] or dispersing lanthanum-aluminate crystals [12] However, the formations of micrometer sized elongated and/or plate-like phases were not always effective to improve the strength due to the enlargement of a flaw size in the composites. On the contrary, using CeTZP of less than $12 \mathrm{~mol} \% \mathrm{CeO}_{2}$ as a ceramic matrix would be effective for the restraint of the toughness degradation of the composites.

The purpose of this investigation is to develop a new attractive Ce-TZP ceramic, which possesses a high strength while still preserving significant high hardness. Furthermore, the effect of starting materials mode of preparation was also investigated. 


\section{MATERIALS AND METHODS}

\section{Mechanically Mixed Samples}

A composition of 85 wt $\% \mathrm{Al}_{2} \mathrm{O}_{3}, 10$ wt $\%$ Y-PSZ and 5 wt $\% \mathrm{CeO}_{2}$ was made by powder mixing. The used aluminum oxide was of purity of $99.98 \%$ (provided by Almatis Gmbh Ludwigshafen/RH, Germany), and cerium (IV) oxide was of purity 99.5\% (from Alfa Aesar UK), while 5 mol\% Y-PSZ was prepared by hydrolysis of zirconium (IV)-n-butoxide (Stream chemicals USA) with the addition of yttrium nitrate $\left(\mathrm{Y}_{2} \mathrm{O}_{3}\right.$ in $\left.\mathrm{HNO}_{3}\right)$. The prepared gel was dried and calcined at $700{ }^{\circ} \mathrm{C}$ to get rid of all organic and nitrate materials. The calcined powder was ground to less than $10 \mu \mathrm{m}$. All powders were mechanically mixed using a ball mill ,5 $\mathrm{mm}$ zirconia balls and polypropylene container with a constant speed of $300 \mathrm{rpm}$ for $5 \mathrm{~h}$.

\section{Sol-Gel Technique}

The same composition was prepared by chemical technique of the precursors of alumina, zirconia and ceria using sol- gel technique. Aluminum tri-isopropoxide was hydrolyzed in distilled water and peptized by nitric acid. $5 \mathrm{~mol} \%$ yttria-partially stabilized zirconia was separately prepared by the hydrolysis of zirconium (IV)-nbutoxide with the addition of yttrium nitrate $\left(\mathrm{Y}_{2} \mathrm{O}_{3}\right.$ in $\left.\mathrm{HNO}_{3}\right)$. $\mathrm{Ce}\left(\mathrm{NO}_{3}\right)_{4} \cdot 4 \mathrm{H}_{2} \mathrm{O}$ was added to the hydrolyzed zirconium and aluminum alkoxide mixtures. The mixture was carefully stirred and allowed to cool till gellation. The formed gel was dried, calcined at $700{ }^{\circ} \mathrm{C}$ and ground to $10 \mu \mathrm{m}$.

\section{Processing}

The powders obtained from both processing routes were formed by uniaxial pressing at $220 \mathrm{MPa}$ into discs of $13 \mathrm{~mm}$ diameter and $4 \mathrm{~mm}$ height (for physical and microstrucural characterization) and rectangular bars of dimensions of $6 \mathrm{~mm} 6$ $\mathrm{mm} \times 60 \mathrm{~mm}$ (for mechanical evaluation). The formed shapes were fired in an electric oven at $1500-1650{ }^{\circ} \mathrm{C}$ with $50{ }^{\circ} \mathrm{C}$ intervals and one hour soaking time. Heating and cooling were conducted using rates of $5^{\circ} \mathrm{C} / \mathrm{min}$.

\section{Characterization}

The densification parameters of the fired samples in terms of bulk density and apparent porosity were evaluated by the liquid displacement method (ASTM C-20). The different phases developed during firing were identified by X-ray analysis (XRD) using a Philips X-ray diffractometer model PW: 1730 apparatus with a $\mathrm{Cu}$ target and $\mathrm{Ni}$ filter. Microstructure of the fracture etched surfaces was examined using scanning electron microscope (SEM-Jeol JSM-T20) apparatus coupled with an energy dispersion spectroscopy (EDS) equipment. Vickers hardness measurements were carried out for sintered samples by using micro hardness tester (Omnimet automatic MHK system Model Micro Met 5114, Buehler USA). Indentations were made on polished surfaces with a load of $1 \mathrm{~kg}$ held for $15 \mathrm{~s}$. 30 indents were made for each sample and the average hardness was determined. Composite samples were polished down to $0.25 \mu \mathrm{m}$ surface finish with diamond paste and thermally etched at $1000{ }^{\circ} \mathrm{C}$ for $1 \mathrm{~h}$ in air atmosphere. Bending strength was measured using a three point bending test on a universal testing machine (Model LLOYD LRX5K of capacity 
$5 \mathrm{KN}$ ) at a crosshead speed of $0.05 \mathrm{~mm} / \mathrm{min}$, and support distance of $25 \mathrm{~mm}$. At least 10 specimens with the dimensions of $6 \mathrm{~mm} \times 6 \mathrm{~mm} \times 60 \mathrm{~mm}$ were measured for each data point. The thermal conductivity of the materials was calculated as One Dimensional Fin. Accordingly the following steps were carried out:

(1) Building a model for both $\mathrm{HX}$ and $\mathrm{MX}$ with a dimension $(3 \times 3 \times 30) \mathrm{mm}^{3}$

(2) Simulate application of heat source at root end with temperature (100 $\left.{ }^{\circ} \mathrm{C}\right)$.

(3) Tracing the temperature drop and distribution along the depth of the heated specimen.

(4) Comparing the temperature distribution of both materials with a similar geometrical shape specimen made from pure alumina.

(5) Applying heat transfer relation dealing with one dimensional fin.

$$
\left(\mathrm{t}_{\mathrm{x}}=\mathrm{t}_{\mathrm{r}} \mathrm{e}^{-\mathrm{mx}}\right)
$$

where $t_{x}$ is the temperature at distance $x$ from the root in $\left({ }^{\circ} \mathrm{C}\right), t_{r}$ is the Root temperature in $\left({ }^{\circ} \mathrm{C}\right), \mathrm{m}$ is the variable coefficient, $m=(h . P / k . A)^{1 / 2}, h$ is the heat transfer due to convection $\left(\mathrm{W} / \mathrm{m}^{2} \mathrm{~K}\right), \mathrm{P}$ is the premeter of the fin function of the geometry of the fin itself $(m), k$ is the thermal conductivity of the fin material $(\mathrm{W} / \mathrm{m} . \mathrm{K})$ and $A$ is perpendicular area $\left(\mathrm{m}^{2}\right)$.

(6) Getting the thermal conductivity of the prepared specimen.

\section{RESULTS AND DISCUSSION}

Figure 1 ( $\mathrm{a}, \mathrm{b}$ and $\mathrm{c}$ ) shows bright and dark field of TEM micrographs of the as received $\mathrm{Al}_{2} \mathrm{O}_{3}$ and $\mathrm{CeO}_{2}$ powders. It is obvious that the size of $\mathrm{Al}_{2} \mathrm{O}_{3}$ particles is 138.9 - $133.4 \mathrm{~nm}$ with a narrow size distribution. $\mathrm{CeO}_{2}$ shows a very fine particle size ranging between 36.7 and $13.5 \mathrm{~nm}$. The TEM micrograph of the $\mathrm{ZrO}_{2}$ gel calcined at $700{ }^{\circ} \mathrm{C}$ revealed that the calcined $\mathrm{ZrO}_{2}$ gel is composed of a very fine particles agglomerated into large particles. The most common type of agglomerates is due to solid bonds formed between particles, Fig 1 (c).

The densification behavior of the samples in terms of bulk density and apparent porosity is illustrated in Fig 2. HX samples prepared via sol-gel route give the higher bulk density and lower apparent porosity. The figure shows that there is a gradual increase in the bulk density and decrease in the apparent porosity of both $\mathrm{HX}$ and MX (mechanically mixed) samples when they fired up to $1600{ }^{\circ} \mathrm{C}$. As the firing temperature increases to $1650{ }^{\circ} \mathrm{C}$ the density is sharply increases with a sudden decrease of the apparent porosity.

The densification parameters of mechanically mixed samples are less than those prepared via sol-gel route. The improvement in the densification parameters of $H X$ samples is due to their fine grain size. A study carried out by James [13] showed that the densification of a powder body is dependent upon a number of powder characteristics such as, the material features and the geometrical features. We believe that the good homogeneity of the sol-gel prepared samples played an important role in the improvement of their densification behavior. 
XRD patterns of $\mathrm{HX}$ and $\mathrm{MX}$ samples sintered at $1650{ }^{\circ} \mathrm{C}$ for 1 hour are shown in Fig 3. X-ray patterns indicate the presence of corundum, t-zirconia and cerium - zircon oxide $\left(\mathrm{Ce}_{2} \mathrm{Zr}_{3} \mathrm{O}_{10}\right)$. $\mathrm{CeAlO}_{3}$ phase is not detected in both samples ( $\mathrm{HX}$ and $\mathrm{MX}$ ). The absent of $\mathrm{CeAlO}_{3}$ phase can be explained by the results obtained by Damyanova et al. [14], who stated that $\mathrm{CeAlO}_{3}$ phase appears only at high reduction temperatures. A slight shift of the (101), (103) and (211) peaks of tetragonal zirconia was noticed. It indicates a slight increase of the lattice dimensions. The slight increase in the lattice dimensions suggests that $\mathrm{Ce}^{4+}$ ions has formed a solid solution in ZTA ceramic specially for $(\mathrm{Zr}, \mathrm{Y}) \mathrm{O}_{2}$ phase as ionic radius of $\mathrm{Ce}^{4+}$ is close to that of $\mathrm{Y}^{3+}\left(\mathrm{Ce}^{4+}: 0.96\right.$ $\AA$ and $Y^{3+}: 0.92 \AA$ ) [15]. XRD patterns prove the existence of $\mathrm{Ce}_{2} \mathrm{Zr}_{3} \mathrm{O}_{10}$ phase.

A representative microstructure of sol-gel prepared composites fired at $1650^{\circ} \mathrm{C}$, shown in Fig 4, reveals the uniformly distribution of $\mathrm{ZrO}_{2}$ grains (light grains) in darker $\mathrm{Al}_{2} \mathrm{O}_{3}$ matrix. As seen in the figure many zirconia grains coarsened by coalescence in the absence of a liquid phase. The incorporation of higher stabilizing oxides content, $\mathrm{Y}_{2} \mathrm{O}_{3}$ and $\mathrm{CeO}_{2}$ led to agglomeration of zirconia particles resulting in heterogeneous microstructure [16]. The formation of $\mathrm{Ce}_{2} \mathrm{Zr}_{3} \mathrm{O}_{10}$ phase is presented in Fig 5 (a) as spheres embedded in alumina grains. Energy-dispersive X-ray analysis (EDX) given in Fig 5 (b) confirms the above mentioned result. It shows that such particles are composed of alumina, zirconia and ceria. Dislocations were visible in alumina grains, whether the samples is prepared via sol-gel or mixing technique and they are mainly present inside the grain, Figs. 6 and 7. Frequently dislocations appeared to initiate from grain boundaries. It is often traversed the grain, starting from one boundary and ending at the opposite boundary. If there is a dispersion of small particles or impurity atoms in the microstructure, the moving dislocation will be pinned, and thus form a curved shape [17].

The dislocation model of Ball and Hutchison [18] appears to be consistent with the studied samples. This model is based on the concept that although during high temperature deformation grains can slide, rotate, or rearrange their position to enable deformation. Grains that are unfavorably oriented or with irregular grain shapes could obstruct the easy relative motion of groups of grains that are sliding under applied stress. Thus, the shear stress becomes concentrated at any grain, triple point, or protrusion that obstructs motion of group. This local high stress can then generate dislocations in the blocking grain. The generated lattice dislocations traverse the blocking grains and pike-up against the opposite grain boundary. The formation of well-elongated grains of alumina was observed in the composites prepared via mechanically mixing route Fig 8.

The formation of cerium zirconate with pyrochlore structure, $\mathrm{Ce}_{2} \mathrm{Zr}_{3} \mathrm{O}_{10}$ with alumina matrix is shown in Fig 9. As evident from the figure the $\mathrm{Ce}_{2} \mathrm{Zr}_{3} \mathrm{O}_{10}$ phase is appeared as white porous latches. Energy dispersion X-ray analysis (EDX) in Fig 9 reveals the formation of $\mathrm{Ce}_{2} \mathrm{Zr}_{3} \mathrm{O}_{10}$ phase.

Table 1 shows the mechanical properties of uniaxially formed samples in terms of three point bending strength and Vickers hardness. Based on the test results of the mechanical properties, the sol-gel technique can be concluded to increase the values of the mechanical properties. This increase of the mechanical properties is mainly due to the higher densification of the sol-gel prepared samples Fig 2(b). 
Higher densification of the ceramic body will remove porosity. Porosity affects the strength in two ways. First, porosity produces stress concentration points, once the stress reaches a critical level, a crack will form and propagate. Because ceramic passes no plastic deformation attributes to absorb any energy transferred to this material once a crack is initiated, it propagates until fracture occurs. Second, pores reduce the strength of ceramic because they reduce the cross-section areas which a load can be applied and consequently, lower the stress that these materials can support [15]. It is well known that the non-densified grain structure reduce the mechanical properties of the ceramic body $[19,20]$, in addition, the lower mechanical properties values of the mechanically mixed samples in comparison to sol-gel samples can be attributed to their irregular geometry and elongated shape Fig 9. It is demonstrated by Daguano et al [5] that reducing the number of grains per area, causes a smaller degree of crack deflection by the grains boundaries and enhances the mechanical resistance of the bodies.

Thermal conductivity is considered one of the most important material properties and controls its applications. The thermal conductivity is very sensitive to material porosity. In the current study the two different techniques lead to different porosity figures $(7.61 \%$ for $\mathrm{HX}$ and 10.36 for $\mathrm{MX})$. The two studied materials were investigated to get the overall thermal conductivity. The case studied here is a combination between conduction and convection [21]. The conduction took place through the dense materials either $\mathrm{HX}$ or $\mathrm{MX}$, keeping in mind the effect of the material porosity, as the porosity affects negatively the thermal conductivity. Based on the theoretical density and thermal conductivity data of the phases comprising the material and the data given in Table 1, conductivity coefficient was calculated. The applied model shows a thermal conductivity of $17.55 \mathrm{~W} / \mathrm{m} . \mathrm{K}$ for $\mathrm{HX}$ and $14.39 \mathrm{~W} / \mathrm{m} . \mathrm{K}$ for MX compared with $30 \mathrm{~W} / \mathrm{m}$.K for pure alumina. The thermal conductivity drop is due the additives used specially the rare earth elements which help in scattering the thermal waves through the material as well as the significant effect of the porosity due to production techniques used. It is interesting to note that experimentally measured thermal conductivity of $8 \mathrm{YSZ}$ is $2.3 \mathrm{~W} /(\mathrm{m} . \mathrm{K})$, while the theoretically predicted value is $3.2 \mathrm{~W} /(\mathrm{m} \mathrm{K})$ [22]. Raghavan et al. [23] stated in their study that the thermal conductivity of $20 \mathrm{Y}(\mathrm{Ta}$ or $\mathrm{Nb}) \mathrm{O}_{4}$ doped zirconia is similar to that seen in commonly used 4.2 mol\% YSZ.

\section{CONCLUSIONS}

1- Vickers hardness and bending strength of the sol-gel prepared composites are higher than those of the mechanically mixed composites.

2- Based on the theoretical density of zirconia, alumina and ceria, thermal conductivity and porosity data of the studied material, the thermal conductivity coefficient $\left(h_{i}\right)$ of the studied materials was estimated to be 17.55 and 14.39 $\mathrm{W} /(\mathrm{m} . \mathrm{K})$ for $\mathrm{HX}$ and $\mathrm{MX}$ respectively.

3- Sol-gel prepared composites reveal uniformly distribution of $\mathrm{ZrO}_{2}$ grains in $\mathrm{Al}_{2} \mathrm{O}_{3}$ matrix. 


\section{REFERENCES}

[1] Dong YL, Xu FM, Shi XL, Zhang C, Yang JM, Tan Y. Fabrication and mechanical properties of nano-/micro - sized $\mathrm{Al}_{2} \mathrm{O}_{3} / \mathrm{SiC}$ composites. Mater Sci Eng A 2009; 504: 49-54.

[2] Awaad M, Khalifa T, Naga SM, Ibrahim NA. Fiber - Reinforced Alumina Based Composites Using Nonwoven Cellulose Fabrics. Am Ceram Soc Bull 2005; 84 [4]: 1-6.

[3] Anya CC. Microstructural nature of strengthening and toughening in $\mathrm{Al}_{2} \mathrm{O}_{3}-$ SiC (p) nanocomposites. J Mater Sci. 1999; 34: 5557-5567.

[4] Shukla S, Seal S, Vij R, Bandyopadhyay S, Rahman Z. Effect of nanocrystallite morphology on the metastable tetragonal phase stabilization in zirconia. Nano Lett 2002; 2 [9]: 989-993.

[5] Daguano JKMF, Santos S, Souza RC, Balestra RM, Strecker KECN. Properties of $\mathrm{ZrO}_{2}-\mathrm{Al}_{2} \mathrm{O}_{3}$ composite as a function of isothermal holding time. Int J Refract Met Hard Mater 2007; 25: 374-379.

[6] $\mathrm{Xu} \mathrm{CH}, \mathrm{Ai}$ X, Huang CZ. Applications of rare earth elements in oxide, carbide and boride ceramic materials. Bull. Chin. Ceram. Soc. 17 [3] (1998) 64-68.

[7] C.H.Xu, X.Ai. C.Z.Huang, "Mechanical property and cutting performance of yttrium reinforced $\mathrm{Al}_{2} \mathrm{O}_{3} / \mathrm{Ti}(\mathrm{CN})$ composite ceramic tool materials. J Mater Eng Perform 2001; 10 [1]: 102-107.

[8] Balagopal N, Warrier KGK, Damodaran AD. Alumina-ceria composite powders through a flash combustion technique. J Mater Sci Lett. 1991; 10: 1116-1118.

[9] Akin I, Yilmaz E, Sahin F, Yucel O, Goller G. Effect of $\mathrm{CeO}_{2}$ addition on densification and microstructure of $\mathrm{Al}_{2} \mathrm{O}_{3}-\mathrm{YSZ}$ composites. Ceram Inter 2011; 37: 3273-3280.

[10] Tsai JF, Chon U, Ramachandran N, Shetty DK. Transformation plasticity, toughening in $\mathrm{CeO}_{2}$-partially-stabilized zirconia-alumina (Ce-TZP/ $\mathrm{Al}_{2} \mathrm{O}_{3}$ ) composites doped with MnO. J Am Ceram Soc 1992; 75 [5]: 1229-1238.

[11] Culter RA, Mayhew RJ, Prettyman KM, Virkar AV. High-toughness Ce$\mathrm{TZP} / \mathrm{Al}_{2} \mathrm{O}_{3}$ ceramics with improved hardness and strength. J Am Ceram Soc 1991; 74: 179-186.

[12] Miura M, Hongoh $H$, Yogo T, Hirano S, Fujii T. Formation of plate-like lanthanum-aluminate crystal in Ce-TZP matrix. J Mater Sci 1994; 29: 262-268.

[13] James PJ. Particle deformation during cold isostatic pressing of metal powders. Powder metal 1977; 20 [4]: 199-203.

[14] Damyanova S, Perej CA, Schamal M, Bueno JMC. Characterization of ceriacoated alumina carrier. Appl Catal A Gen. 2002; 234: 271-282

[15] Rejab NA, Azhan AZA, Ratnam MM, Ahmed ZA. The effect of $\mathrm{CeO}_{2}$ addition on the physical, microstructure and mechanical properties of yetria stabilized zirconia toughened alumina (ZTA). Int J Refract Metals Hard Mater 2013, 36: 162-166.

[16] Itatani K, Abiro T, Aizawa M, Howell FS, Kishioka A. Sintering of mullitezirconia composite powder prepared by ultrasonic spray pyrolysis technique. J M Syn Pnoc 1998; 6 [3]: 221-225.

[17] Xum Y, Mohamed FA. Superplastic behavior of Zn-22\% Al containing monoscale dispersion particles. Acta Mater 2004; 52: 4401-4412.

[18] Ball A, Hutchinson MM. Super plasticity in the alumina-zinc eutectaid. Met Sci J 1969, 3: 1-6. 
[19] Rice RW. Mechanical properties of ceramics and composites grain and particle effects. New York: Marcel Dekker; 2000.

[20] Rajendran S, Rassell HJ. Co precipitation - deried mullite and mullitezirconia composites. J Mater Sic. 1991; 26: 5815-5822.

[21] J. P. Holman. Heat Transfer. $10^{\text {th }}$ edition, New York: McGraw-Hill; 2010; P: 45-57.

[22] Raghavan S, Wang H, Dinwiddie RB, Porter WD, Mayo MJ. The effect of grain size, porosity and yttria content on the thermal conductivity of nano crystalline zirconia. Scr Mater 1998; 39 [8]: 1119-1125.

[23] Raghavan S, Wang H, Dinwiddie RB, Porter WD, Mayo MJ. Thermal properties of zirconia co-doped with trivalent and pentavalent oxides. Acta Mater 2001; 49: 69-179. 


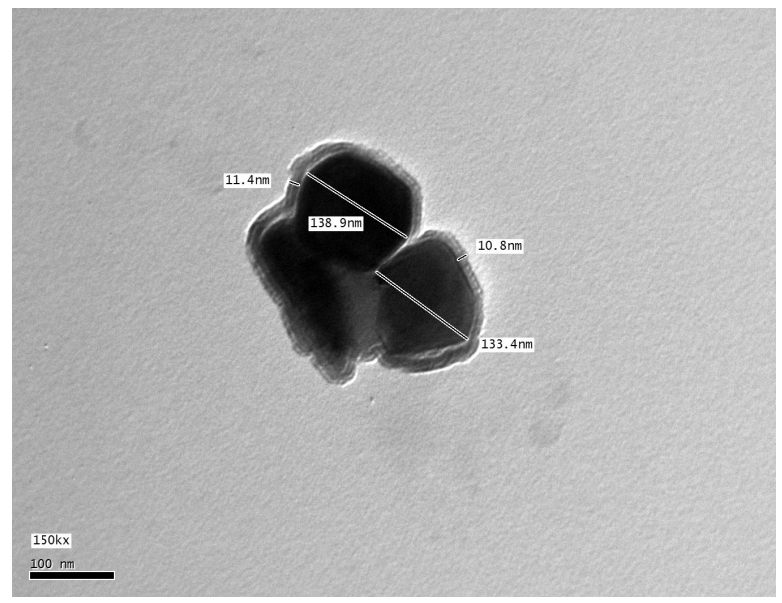

(a)

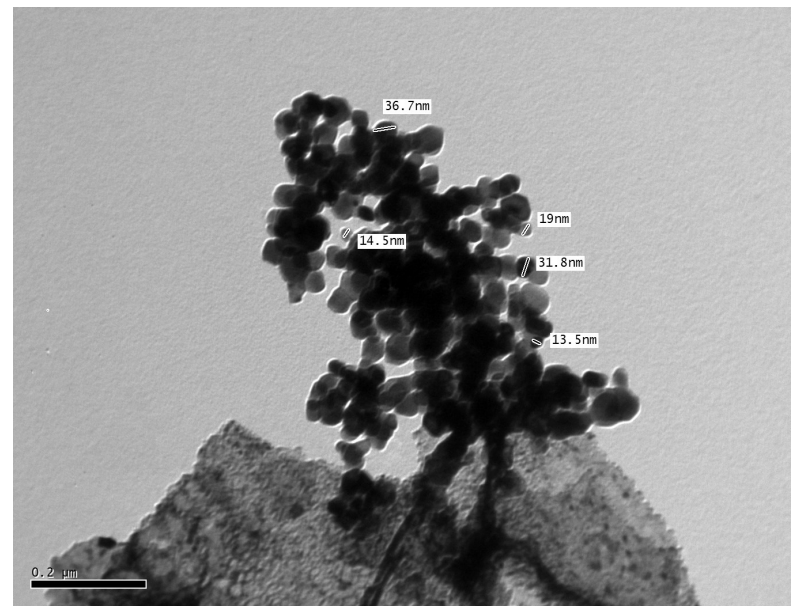

(b)

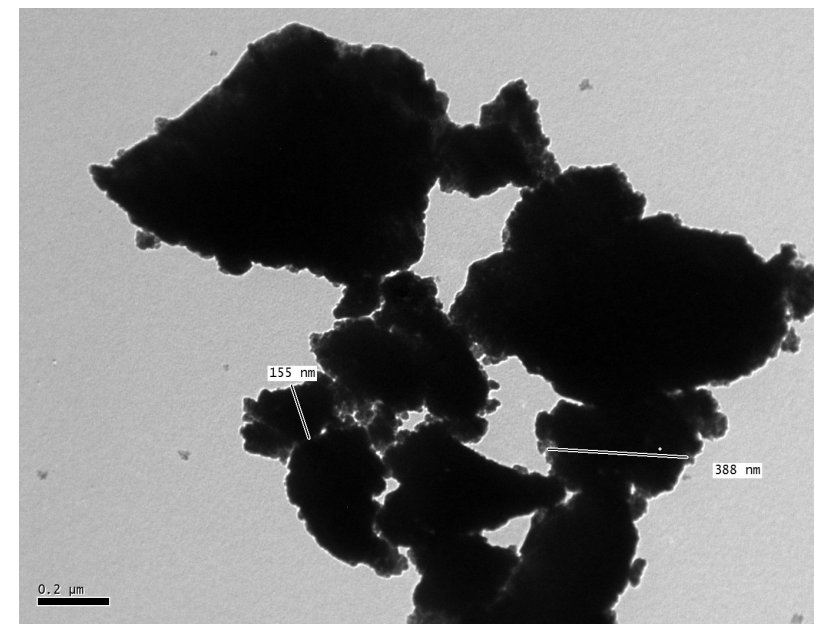

(c)

Fig.1. TEM for the starting materials, (a) Alumina, (b) Ceria and (c) Zirconia. 


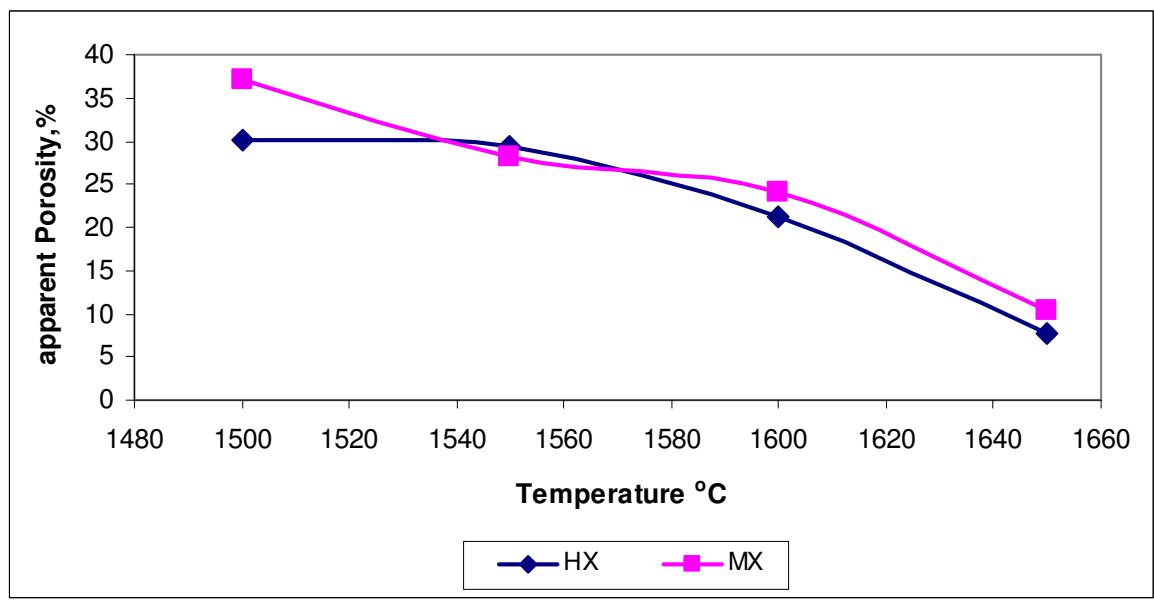

(a)

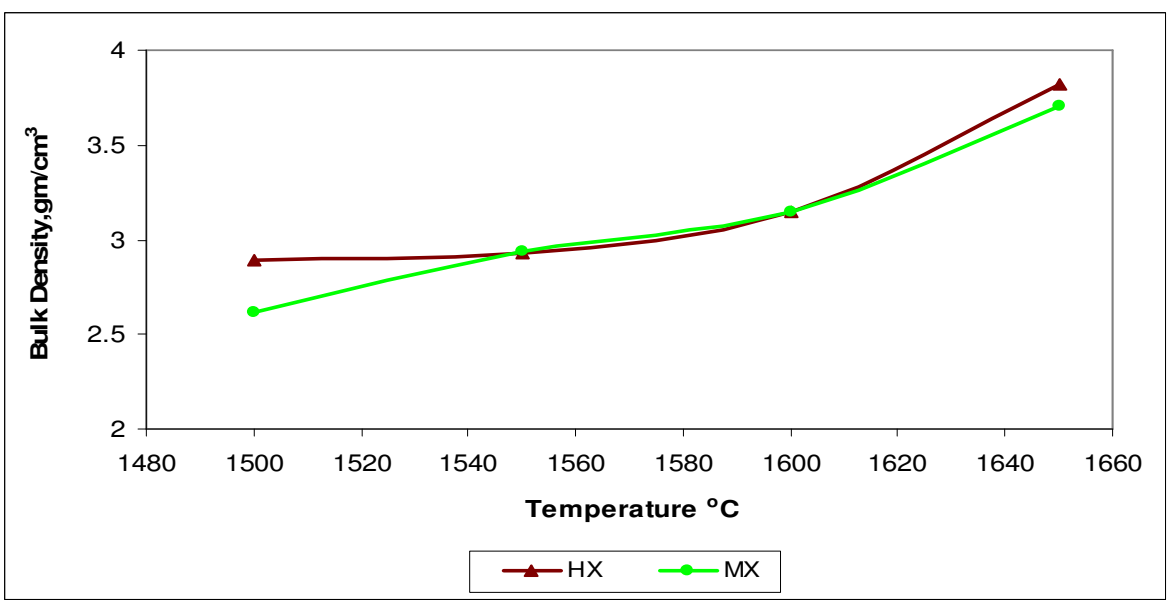

(b)

Fig. 2. Physical properties of the fired composites fired at different firing temperatures, (a) Apparent porosity and (b) Bulk density.

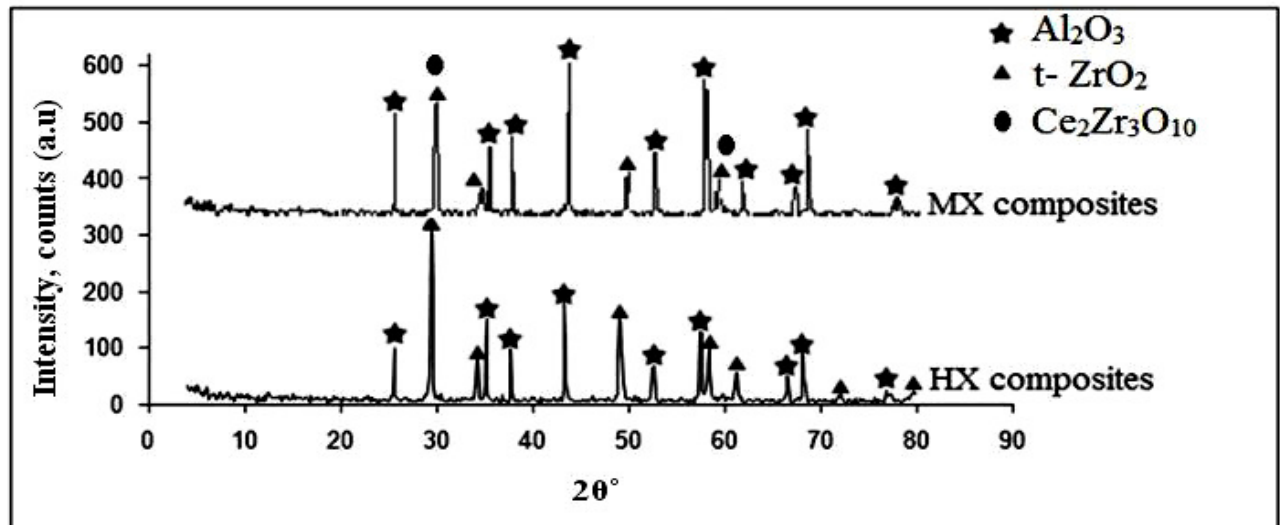

Fig. 3. X-ray patterns of the sintered $\mathrm{HX}$ and $\mathrm{MX}$ composites sintered at $1650^{\circ} \mathrm{C}$. 


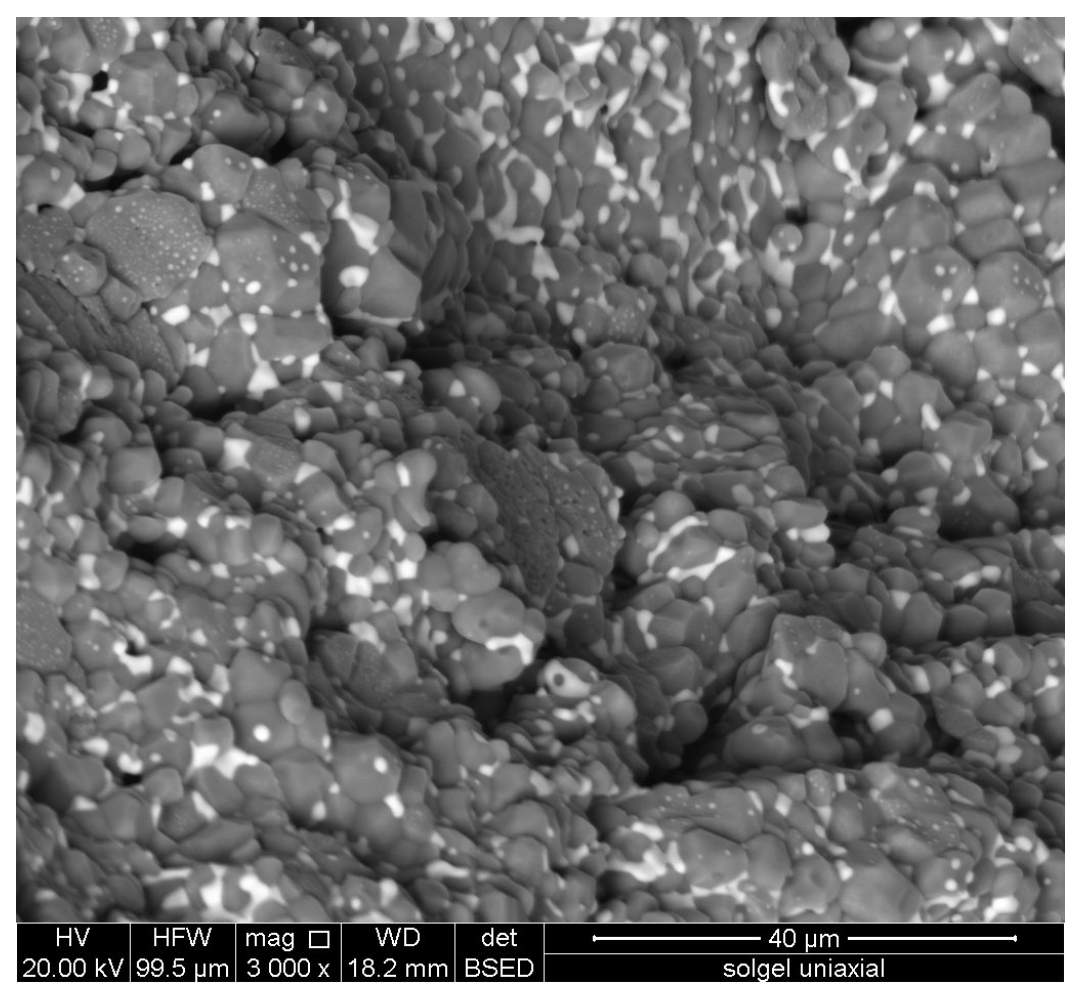

Fig.4. SEM micrograph of $\mathrm{HX}$ composites fired at $1650^{\circ} \mathrm{C}$.

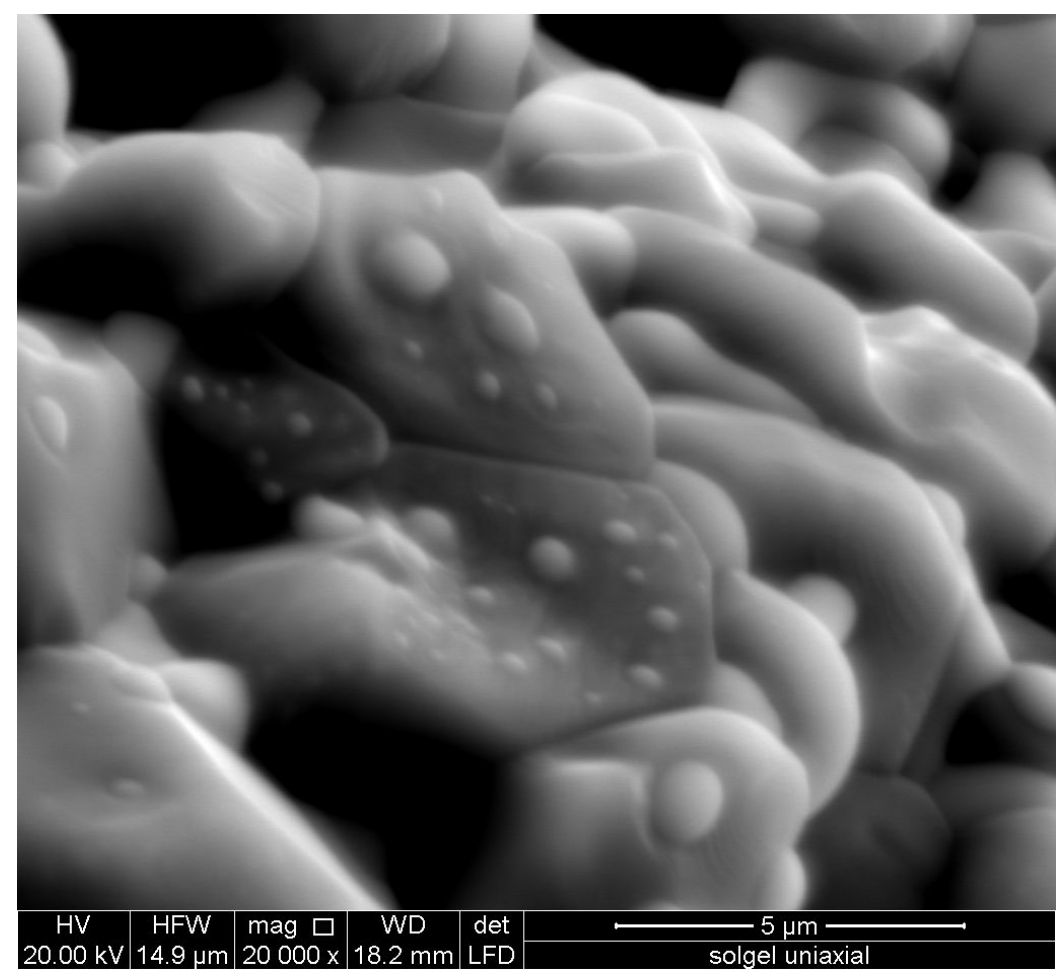

(a) 


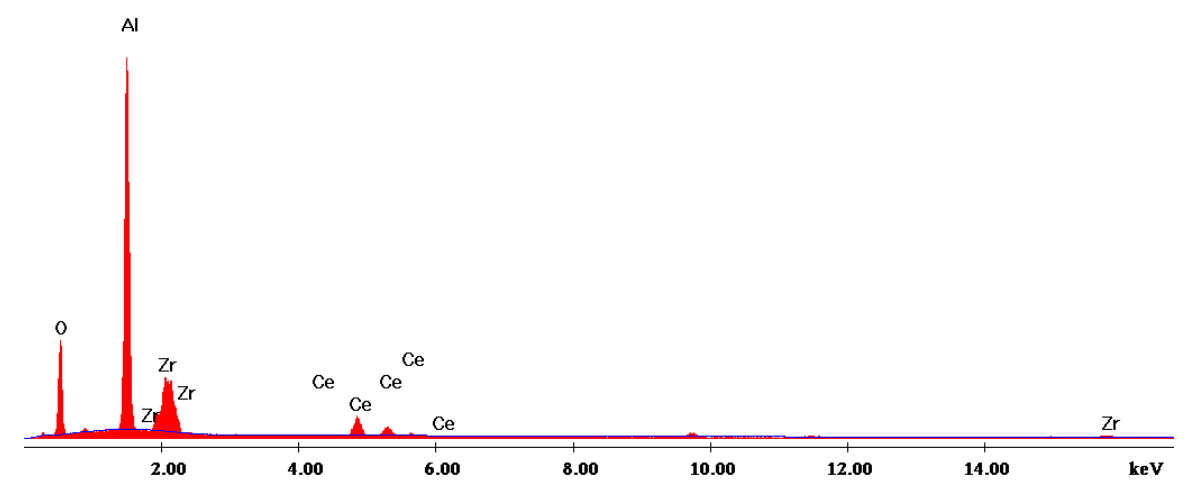

(b)

Fig.5. SEM micrograph of: (a) $\mathrm{Ce}_{2} \mathrm{Zr}_{3} \mathrm{O}_{10}$ grains embedded in $\mathrm{Al}_{2} \mathrm{O}_{3}$ grains and (b) EDX of $\mathrm{Ce}_{2} \mathrm{Zr}_{3} \mathrm{O}_{10}$ grains.

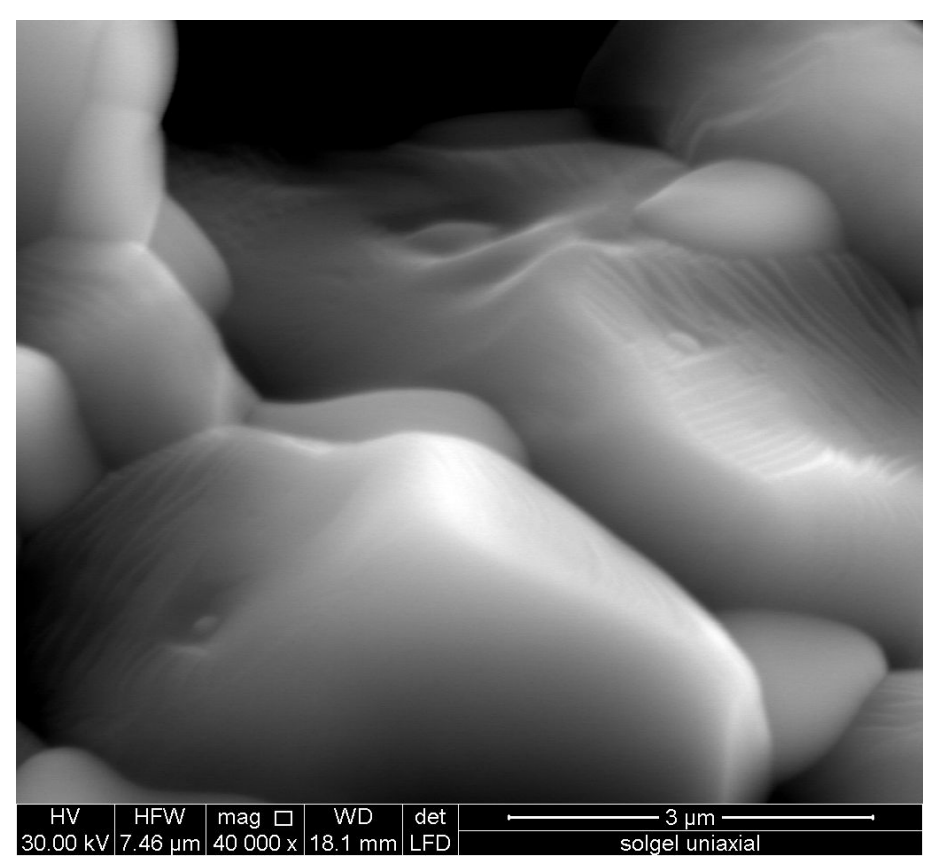

Fig.6. SEM micrograph of $\mathrm{HX}$ composites shows the dislocation in the alumina grains. 


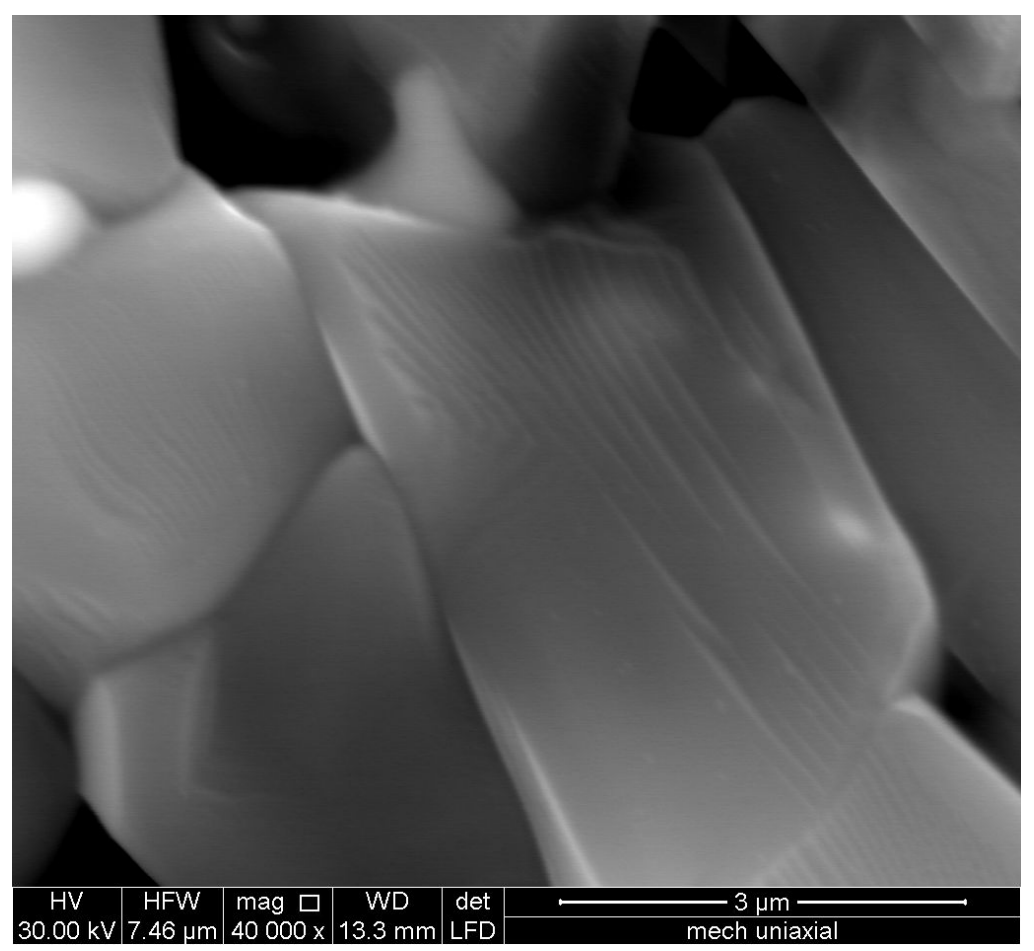

Fig.7. SEM micrograph of MX composites shows the dislocation in the alumina grains.

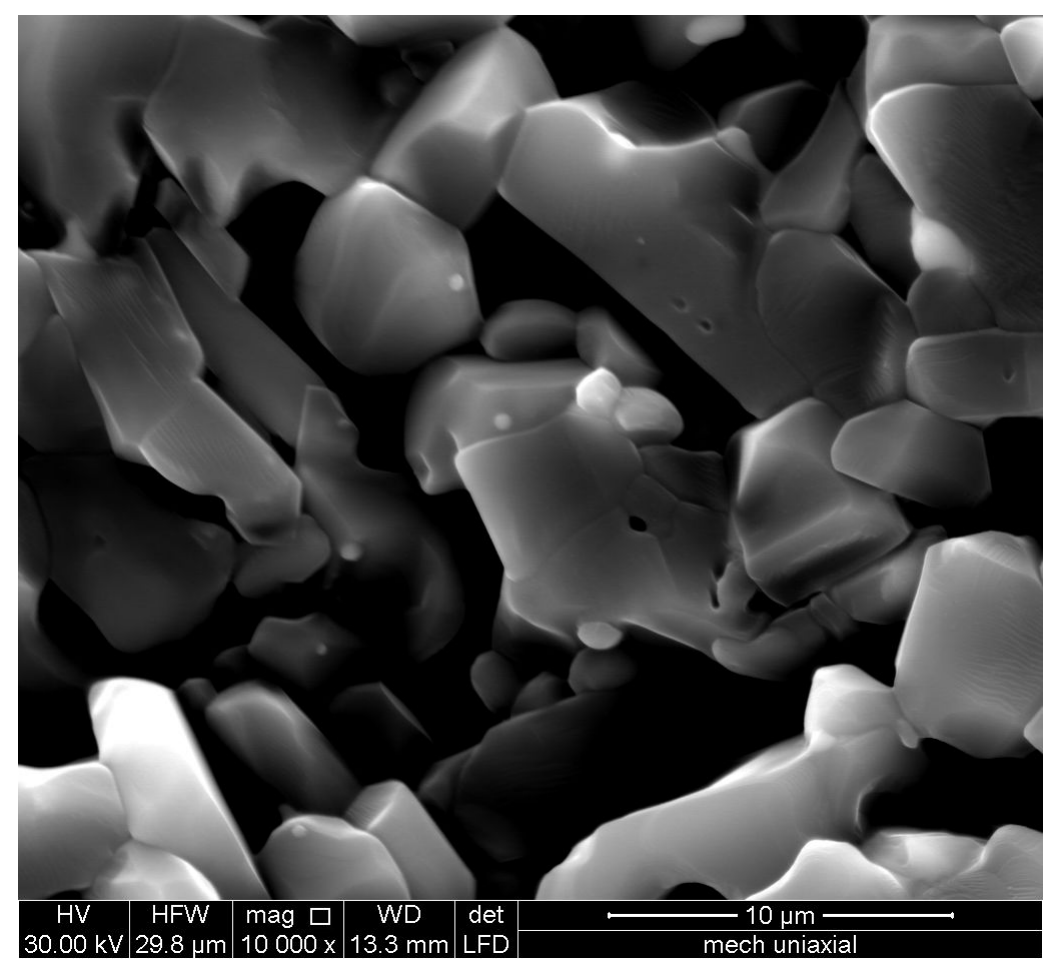

Fig.8. SEM micrograph of MX composites fired at $1650^{\circ} \mathrm{C}$, shows elongated alumina grains. 

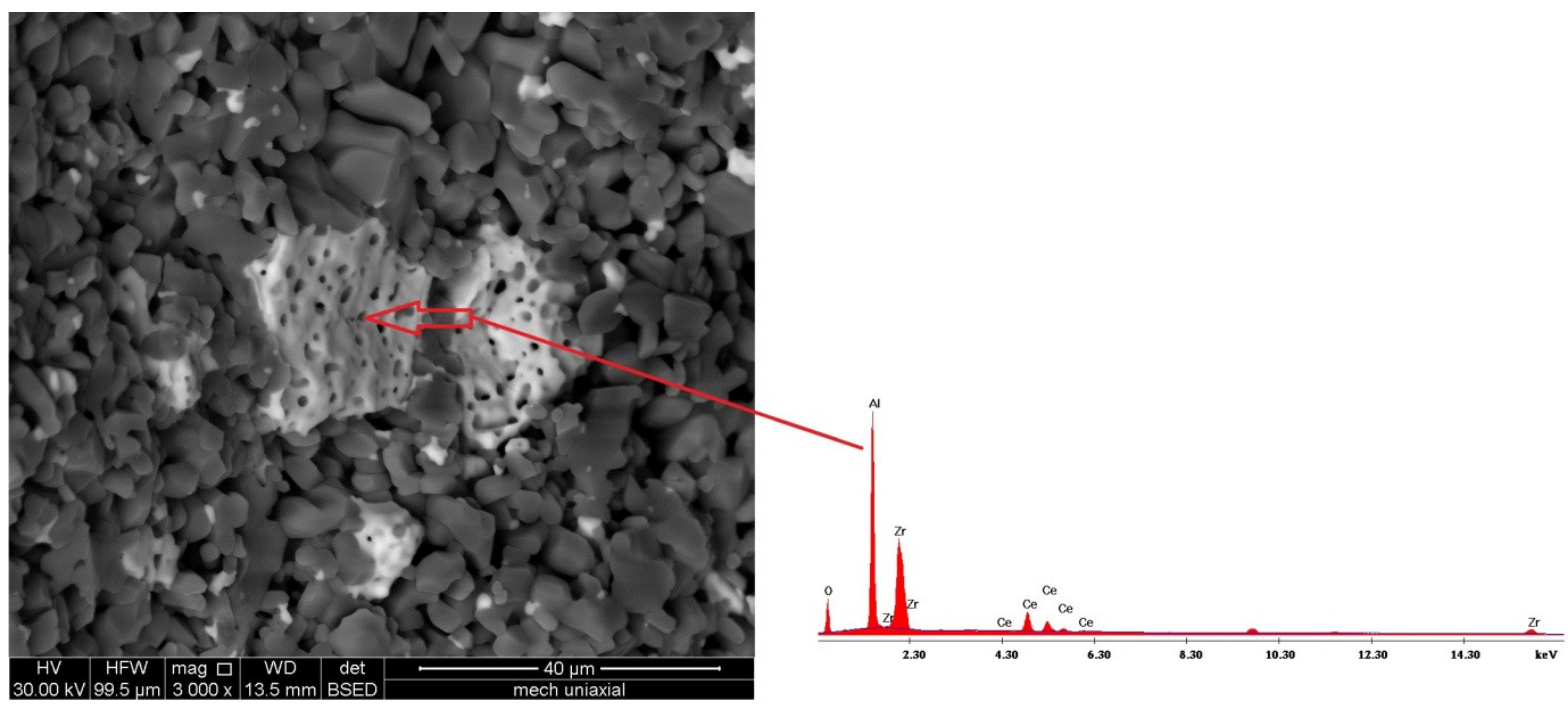

Fig.9. SEM micrograph of $\mathrm{MX}$ composites fired at $1650^{\circ} \mathrm{C}$ with EDX pattern.

Table 1. Physical and mechanical properties of the sintered samples.

\begin{tabular}{|c|c|c|c|c|c|}
\hline $\begin{array}{c}\text { Sample } \\
\text { symbol }\end{array}$ & $\begin{array}{c}\text { Apparent } \\
\text { porosity }(\%)\end{array}$ & $\begin{array}{c}\text { Bulk density } \\
\left(\mathrm{g} / \mathrm{cm}^{3}\right)\end{array}$ & $\begin{array}{c}\text { Theoretical } \\
\text { density } \\
(\%)\end{array}$ & $\begin{array}{c}\text { Vickers } \\
\text { hardness Hv }\end{array}$ & $\begin{array}{c}\text { Bending } \\
\text { strength } \\
(\mathrm{MPa})\end{array}$ \\
\hline HX & 7.61 & 3.82 & 89.25 & 940.93 & 164.17 \\
\hline MX & 10.36 & 3.70 & 86.45 & 829.37 & 156.69 \\
\hline
\end{tabular}

